\title{
Compositional Analysis of Biofilms Formed by Staphylococcus aureus Isolated from Food Sources
}

\author{
Elena-Alexandra Oniciuc ${ }^{1,2}$, Nuno Cerca $^{2}$ and Anca I. Nicolau ${ }^{1 *}$ \\ ${ }^{1}$ Faculty of Food Science and Engineering, Dunarea de Jos University of Galati, Galati, Romania, ${ }^{2}$ Centre of Biological \\ Engineering, Universidade do Minho, Braga, Portugal
}

Sixteen Staphylococcus aureus isolates originating from foods (eight from dairy products, five from fish and fish products and three from meat and meat products) were evaluated regarding their biofilms formation ability. Six strains (E2, E6, E8, E10, E16, and E23) distinguished as strong biofilm formers, either in standard Tryptic Soy Broth or in Tryptic Soy Broth supplemented with $0.4 \%$ glucose or with $4 \% \mathrm{NaCl}$. The composition of the biofilms formed by these $S$. aureus strains on polystyrene surfaces was first inferred using enzymatic and chemical treatments. Later on, biofilms were characterized by

OPEN ACCESS

Edited by:

Romain Briandet,

French National Institute for Agricultural Research, France

Reviewed by:

Giovanni Di Bonaventura,

"G. D'Annunzio" University of

Chieti-Pescara, Italy

Arnaud Bridier,

French Agency for Food, Environmental and Occupational

Health \& Safety, France

*Correspondence:

Anca I. Nicolau

anca.nicolau@ugal.ro

Specialty section:

This article was submitted to

Food Microbiology,

a section of the journal

Frontiers in Microbiology

Received: 05 January 2016 Accepted: 11 March 2016 Published: 30 March 2016

Citation:

Oniciuc E-A, Cerca N and Nicolau Al (2016) Compositional Analysis of Biofilms Formed by Staphylococcus aureus Isolated from Food Sources.

Front. Microbiol. 7:390.

doi: 10.3389/fmicb.2016.00390 confocal laser scanning microscope (CLSM). Our experiments proved that protein-based matrices are of prime importance for the structure of biofilms formed by $S$. aureus strains isolated from food sources. These biofilm matrix compositions are similar to those put into evidence for coagulase negative staphylococci. This is a new finding having in view that scientific literature mentions exopolysaccharide abundance in biofilms produced by clinical isolates and food processing environment isolates of $S$. aureus.

Keywords: Staphylococcus aureus, biofilm, food, CLSM, exopolysaccharide, protein

\section{INTRODUCTION}

Few studies have been reported so far regarding the biofilm formation by Staphylococcus aureus isolated from foods (Di Ciccio et al., 2015) and the impact of the environmental factors encountered in food processing plants on the adherence and biofilm formation (Vázquez-Sánchez et al., 2013; Santos et al., 2014).

In food industry it is important to know the conditions under which $S$. aureus is able to survive, adhere to surfaces and form biofilms (Futagawa-Saito et al., 2006), leading to contamination of food products. In planktonic form, S. aureus does not appear resistant to disinfectants, compared to other bacteria, but it may be among the most resistant ones when is attached to a surface (Fratamico et al., 2009). S. aureus can produce a multilayered biofilm embedded within a glycocalix with heterogeneous protein expression throughout, forming at least two types of biofilms: ica-dependent, mediated by polysaccharide intercellular adhesin (PIA)/poly-N-acetyl-1,6- $\beta$-glucosamine (PNAG), and ica-independent, mediated by proteins (Beloin and Ghico, 2005). Biofilm-associated protein (Bap), which shows global organizational similarities to surface proteins of Gram-negative (Pseudomonas aeruginosa and Salmonella enterica serovar Typhi) and Gram-positive (Enteroccocus faecalis) bacteria (Cucarella et al., 2001), was the first protein that has been found to be involved in biofilm formation by staphylococcal strains isolated from mammary glands in ruminants suffering from mastitis (Speziale et al., 2014). Meanwhile, Foulston et al. (2014) discovered 
that the extracellular matrix of clinical S. aureus biofilms comprises cytoplasmic proteins that associate with the cell surface in response to decreasing $\mathrm{pH}$. Regarding the capacity to form biofilms, Bridier et al. (2010) demonstrated that $S$. aureus strains from different sources (five clinical, two originating from water, two unknown, and one milk isolate from ewes with mastitis) produce biofilms with high bio volumes and high substratum coverage.

Having in view the significant damages caused by biofilms in food industry in general, more studies should be conducted to elucidate formation of such biofilms and to develop countermeasures for their removal from food contact surfaces (Marques et al., 2007). This study was carried out to evaluate the ability of $S$. aureus strains isolated from food products to form biofilms on hydrophobic surfaces at $37^{\circ} \mathrm{C}$, followed by biofilm matrix characterization. The composition of the biofilms formed by $S$. aureus strains on polystyrene surfaces was first inferred using enzymatic and chemical treatments and later confirmed by confocal laser scanning microscope (CLSM).

\section{MATERIALS AND METHODS}

\section{Bacterial Strains}

Sixteen $S$. aureus strains isolated from food products of animal origin ( 8 from dairy products, 5 from fish and fish products and 3 from meat and meat products) (Oniciuc et al., 2015) were tested to show their ability to form biofilms. Prior to inoculation, all strains were transferred from the stock cultures (preserved in $25 \%$ glycerol at $-80^{\circ} \mathrm{C}$ ) to Baird Parker (BP) (Biolife Italiana srl., Milano, Italy) and incubated aerobically at $37^{\circ} \mathrm{C}$ for $24 \mathrm{~h}$. For biofilm assays we used overnight precultures in Tryptic Soy Broth (TSB) (Liofilchem srl., Roseto degli Abruzzi, Italy) incubated aerobically at $37^{\circ} \mathrm{C}$, with shaking.

\section{Media Screening and Biofilm Formation Overtime}

Media screening consisting in TSB with/ without addition of $0.4 \%$ glucose (TSBG) or $4 \% \mathrm{NaCl}$ (TSBN) (Liofilchem srl.) for supporting $24 \mathrm{~h}$ biofilm formation was performed. Glucose (B. Braun Melsungen AG, Melsungen, Germany) sterilized by filtration $(0.22 \mu \mathrm{m})$ was added after autoclaving. Prolonged incubation time $(48,72 \mathrm{~h}$ ) was also performed (Peeters et al., 2007).

Biofilms were grown in 96-well plates tissue cultured (Orange Scientific, Braine-l'Alleud, Belgium) with a total volume of $200 \mu \mathrm{L}$ of TSB, TSBG and TSBN per well and a starting inoculum approximately equal to $10^{6} \mathrm{CFU} / \mathrm{mL}$. Only broth media were introduced in the assay as negative controls, and S. aureus ATCC 25923 as positive control (clinical isolate). The plates were incubated aerobically at $37^{\circ} \mathrm{C}$, on an orbital shaker (ES-20/60 Environmental Shaker BIOSAN) set at $120 \mathrm{rpm}$. Biofilm quantification was performed according to the procedure developed by Stepanović et al. (2000), by using $1 \%$ crystal violet (CV) (Merck KGaA, Darmstadt, Germany). Biofilm formation in the microplates was measured in an ELISA reader set at $570 \mathrm{~nm}$, and values were expressed in optical density (OD) values.

\section{Matrix Characterization}

Biofilm detachment assays were carried out as described by Kogan et al. (2006) and Fredheim et al. (2009) with slight modifications, for six strains capable to form strong biofilms with an $\mathrm{OD}>4 \times \mathrm{OD}_{N C}$. Biofilms were washed twice with $200 \mu \mathrm{L}$ of $0.9 \% \mathrm{NaCl}$ and then treated for $2 \mathrm{~h}$ at $37^{\circ} \mathrm{C}$ without shaking, with $200 \mu \mathrm{L}$ of $40 \mathrm{mM}$ of sodium periodate $\left(\mathrm{NaIO}_{4}\right)$, or 200 $\mu \mathrm{L}$ proteinase $\mathrm{K}(0.1 \mathrm{mg} / \mathrm{mL}$ in $20 \mathrm{mM}$ Tris- $\mathrm{HCl}: 1 \mathrm{mM} \mathrm{CaCl} 2)$. Control wells were filled with $0.9 \% \mathrm{NaCl}$. After treatment, the biofilms were washed once with $200 \mu \mathrm{L}$ of $0.9 \% \mathrm{NaCl}$, and then resuspended into $200 \mu \mathrm{L}$ of $0.9 \% \mathrm{NaCl}$ and dislodged by scraping followed by sonication using a cycle of $5 \mathrm{~s}$ and an amplitude of $22 \%$. Biomass quantification was performed by measuring the $\mathrm{OD}$ at $600 \mathrm{~nm}$ of each sonicated cell suspension. Measuring the OD of sonicated cell suspensions was preferred for this assay as we observed that $\mathrm{NaIO}_{4}$ used to assess polysaccharides reacts unspecific with $\mathrm{CV}$ therefore yielding false positive results.

\section{Biofilm Composition by CLSM}

The composition of $48 \mathrm{~h}$ biofilms was observed by CLSM, exposed to three types of dyes: (i) SYTO dye that stains nucleic acids; (ii) FilmTracer SYPRO Ruby Biofilm Matrix stain (Invitrogen, Paisley, UK), which labels most classes of proteins (Berggren et al., 2000); (iii) wheat germ agglutinin (WGA) conjugated with Oregon Green (Invitrogen), which stains $N$-acetyl-D-glucosamine residues (Wright, 1984). The fluorescence of dyes was detected using the following combination of laser excitation and emission band-pass wavelengths: $476 \mathrm{~nm} / 500-520 \mathrm{~nm}$ for SYTO, $405 \mathrm{~nm} / 655-755 \mathrm{~nm}$ for SYPRO and $459 \mathrm{~nm} / 505-540$ for WGA. After each staining step, the biofilms were gently rinsed with sterile water. The biofilm images were acquired in an Olympus ${ }^{T M}$ FluoView FV1000 confocal laser microscope and biofilms were observed using 40x water-immersion objective. The images were analyzed sequentially using two virtual channels. Three stacks of horizontal images $(640 \times 640$ pixels $)$ were acquired for each biofilm at different areas in the well. Two surfaces of two independent replicates were observed in each CLSM experiment.

\section{RESULTS AND DISCUSSIONS}

Glucose and $\mathrm{NaCl}$ have been previously shown to induce biofilm formation in clinical strains of $S$. aureus (Fratamico et al., 2009). Measuring the effect of $0.4 \%$ glucose and $4 \% \mathrm{NaCl}$ on biofilm formation enabled us to determine the conditions necessary for $S$. aureus strains isolated from food to form biofilms. For most strains, there was not a significant difference within the media used showing a small degree of variability regarding the amount of biomass produced, but overall, six strains (E2, E6, E8, E10, E16, E23; 37.5\%) with OD > 0.4 were distinguished for higher biofilm formation with TSBG (Supplementary Figure 1, left graphic). As the determination of the total biomass over a specific period of time is a common practice for the characterization of biofilms and $S$. aureus biofilms are growing slowly, prolonged incubation times were used in our experiment too. Not surprisingly, quantification of biofilm proved a progressive accumulation of biomass during the 
TABLE 1 | Biomass reduction of $S$. aureus biofilms when using metaperiodate or proteinase $\mathrm{K}$.

\begin{tabular}{lcc}
\hline S. aureus strains & \multicolumn{2}{c}{ Biomass reduction, \% } \\
\cline { 2 - 3 } & With NalO4 & With proteinase K \\
\hline E2 & $23 \pm 10.34$ & $71 \pm 4.1$ \\
E6 & $34 \pm 2.74$ & $71 \pm 0.74$ \\
E8 & $46 \pm 11.07$ & $69 \pm 0.63$ \\
E10 & $20 \pm 6.51$ & $66 \pm 3.5$ \\
E16 & $25 \pm 0.71$ & $64 \pm 1.75$ \\
E23 & $49 \pm 3.71$ & $67 \pm 6.05$ \\
ATCC 25923 & $28 \pm 5.25$ & $9 \pm 1.9$
\end{tabular}

Preformed biofilms were treated with $\mathrm{NalO4}$ or proteinase $\mathrm{K}$ for $2 \mathrm{~h}$ at $37^{\circ} \mathrm{C}$. Control wells were filled with $0.9 \% \mathrm{NaCl}$. Average results $\pm S D$ of eight wells for each strain are shown. The experiments were performed in triplicate. Values of negative controls have been subtracted from the shown values.

analyzed time course (Supplementary Figure 1, right graphic). Based on these findings we further characterized S. aureus biofilms after $48 \mathrm{~h}$ of incubation.

In order to reveal the molecules behind biofilm accumulation, the biofilm chemical compositions were assessed by measuring the ability of $\mathrm{NaIO}_{4}$ or proteinase $\mathrm{K}$ to disperse S. aureus biofilms. Although both ATCC and food isolates have PNAG and proteins in the matrix, proteins prevail on PNAG, thus having a relevant role in maintaining biofilm structure. In this sense, biomass formed by $S$. aureus strains isolated from foods was reduced by $60-70 \%$ when anti-protein agents were used, while a reduction of 20-49\% was obtained in the presence of the anti-polysaccharide agent (Table 1). Proteinase K treatment enhanced dispersion of Bap-positive $S$. aureus biofilms as demonstrated by Shukla and Rao (2013). The disruption effects observed on $48 \mathrm{~h}$ biofilms were similar for all isolates originating from food sources.

Differences were observed in the biofilm disruption pattern when comparing results obtained for biofilms formed by $S$. aureus isolated from food sources with those developed by the clinical isolate $S$. aureus ATCC 25923, presenting a high density of cell clusters embedded in polysaccharides. At present, there are no references to composition of biofilms formed by $S$. aureus isolated from food sources. Literature mentions only biofilms produced by strains of Staphylococcus spp. isolated from a poultry processing plant, which have been described by Ferreira et al. (2014), as containing a significant amount of exopolysaccharides (EPS).

CLSM in conjugation with three different fluorescent dyes was used to differentiate bacterial cells from PNAG and proteins within the biofilm matrix. Qualitative approach was preferred as biofilms obtained were heterogeneous and more than three sections per each biofilm were needed for a meaningful quantification. Biofilm matrices of E8 and E10 formed by $S$. aureus strains isolated from food are represented in Figure 1 in comparison with those formed by the reference strain. These experiments confirmed that proteins are of prime importance for the structure of biofilms formed by $S$. aureus strains isolated from food sources as revealed by the quantitative approach from biofilm disruption assays.

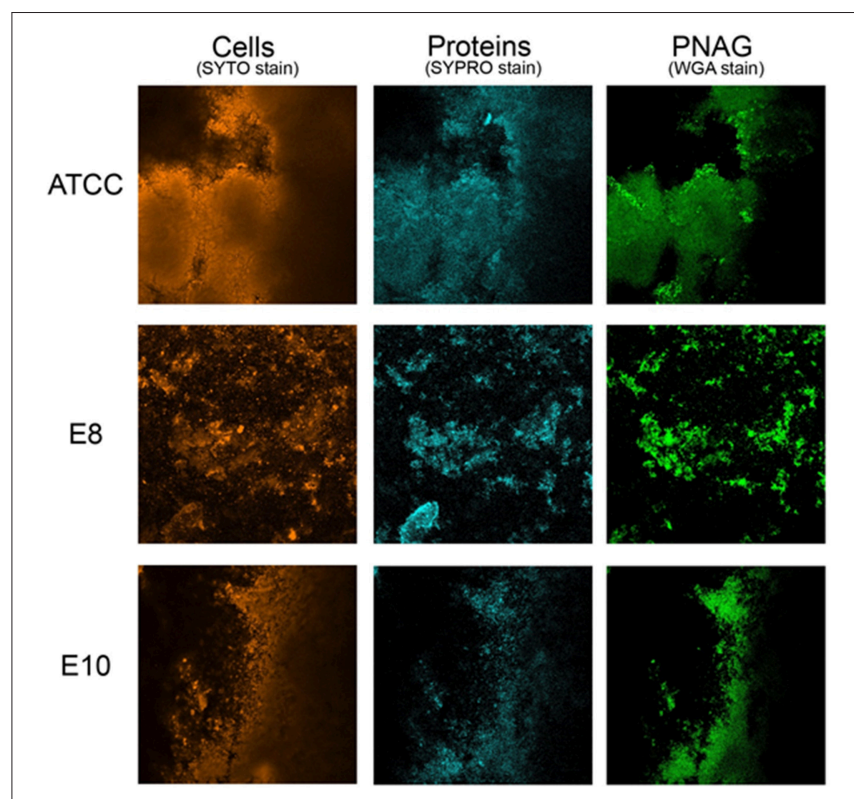

FIGURE 1 | Biofilm matrix structure obtained from confocal microscopy observations of S. aureus ATCC 25923, E8 isolated from poultry, and E10 isolated from artificial red caviar. One z-stack is represented for each biofilm.

\section{CONCLUSIONS AND PERSPECTIVES}

Phenotypic production of EPS by $S$. aureus strains used in the present study suggests that staphylococcal biofilm development may have occurred via an ica-independent pathway. Clearly, in our population of bacteria, PIA independent biofilm formation was more prevalent. Nevertheless, to determine if this characteristic is in fact a key difference between food-borne $S$. aureus and clinical isolates or food processing environment isolates, future research is needed to include a broader range of food-borne isolates.

Presence of biofilm forming strains of $S$. aureus in food and food processing environments is equally important as for the medical sector. Besides causing serious engineering problems as described by Garrett et al. (2008), biofilms are involved in cross contamination events. The proteic extracellular matrix developed by $S$. aureus isolates of food origin can behave in a similar way that the one developed by clinical isolates of $S$. aureus allowing enhanced flexibility and adaptability for this bacterium in forming biofilms and supporting the formation of mixedspecies biofilms either with spoilage or pathogenic bacteria as demonstrated by Foulston et al. (2014). Composition of biofilms has to be known to provide a basis for the development of better strategies for cleaning surfaces and cross contamination avoidance.

\section{AUTHOR CONTRIBUTIONS}

All three authors contributed equally to the following sections: Introduction, Results and Discussions and Conclusions 
and Perspectives. EO wrote Materials and Method section together with NC and prepared the graphs shown in Supplementary Figure 1. NC prepared Figure 1. AN wrote the abstract and prepared the table. Several versions of the manuscript circulated between the authors until they all agreed on the final version.

\section{ACKNOWLEDGMENTS}

This study was supported by the COST Action FA1202 through the STSM-FA1202-100315-058004. We thank to Ângela França (Universidade do Minho, Portugal) for the technical support provided. The support of Anca Gâţă (Dunarea de Jos University

\section{REFERENCES}

Beloin, C., and Ghico, J. M. (2005). Finding gene-expression patterns in bacterial biofilms. Trends Microbiol. 13, 16-19. doi: 10.1016/j.tim.2004. 11.008

Berggren, K., Chernokalskaya, E., Steinberg, T. H., Kemper, C., Lopez, M.F., Diwu, Z., et al. (2000). Background-free, high sensitivity staining of proteins in one- and two-dimensional sodium dodecyl sulfate-polyacrylamide gels using a luminescent ruthenium complex. Electrophoresis 21, 2509-2521. doi: 10.1002/1522-2683(20000701)21:12<2509::AID-ELPS2509>3.0.CO;2-9

Bridier, A., Dubois-Brissonnet, F., Boubetra, A., Thomas, V., and Briandet, R. (2010). The biofilm architecture of sixty opportunistic pathogens deciphered using a high throughput CLSM method. J. Microbiol. Methods 82, 64-70. doi: 10.1016/j.mimet.2010.04.006

Cucarella, C., Solano, C., Valle, J., Amorena, B., Lasa, I., and Penadés, J. R. (2001). Bap, a Staphylococcus aureus surface protein involved in biofilm formation. J. Bacteriol. 183, 2888-2896. doi: 10.1128/JB.183.9.2888-2896.2001

Di Ciccio, P., Vergara, A., Festino, A. R., Paludi, D., Zanardi, E., Ghidini, S., et al. (2015). Biofilm formation by Staphylococcus aureus on food contact surfaces: relationship with temperature and cell surface hydrophobicity. Food Control 50, 930-936. doi: 10.1016/j.foodcont.2014.10.048

Ferreira, A. A., Souza Tette, P. A., Santos Mendonça, R. C., de Souza Soares, A., and De Carvalho, M. M. (2014). Detection of exopolysaccharide production and biofilm-related genes in Staphylococcus spp. isolated from a poultry processing plant. Food Sci. Technol. 34. doi: 10.1590/1678-457x.6446

Foulston, L., Elsholz, A. K., DeFrancesco, A. S., and Losick, R. (2014). The extracellular matrix of Staphylococcus aureus biofilms comprises cytoplasmic proteins that associate with the cell surface in response to decreasing $\mathrm{pH}$. MBio 5:e1667-14. doi: 10.1128/mBio.01667-14

Fratamico, P. M., Annous, B. A., and Guenther, N. W. (2009). Biofilms in the Food and Beverage Industries. Oxford; Cambridge; Philadelphia; New Delhi: Woodhead Publishing Limited.

Fredheim, E. G., Klingenberg, C., Rohde, H., Frankenberger, S., Gaustad, P., Flaegstad, T., et al. (2009). Biofilm formation by Staphylococcus haemolyticus. J. Clin. Microbiol. 47, 1172-1180. doi: 10.1128/JCM.01891-08

Futagawa-Saito, K., Ba-Thein, W., Sakurai, N., and Fukuyasu, T. (2006). Prevalence of virulence factors in Staphylococcus intermedius isolates from dogs and pigeons. BMC Vet. Res. 2:4. doi: 10.1186/1746-6148-2-4

Garrett, T. R., Bhakoo, M., and Zhang, Z. (2008). Bacterial adhesion and biofilms on surfaces, Prog. Natural Sci. 18, 1049-1056. doi: 10.1016/j.pnsc.2008. 04.001

Kogan, G., Sadovskaya, I., Chaignon, P., Chokr, A., and Jabbouri, S. (2006). Biofilms of clinical strains of Staphylococcus aureus that do not contain polysaccharide intercellular adhesin, FEMS Microbiol. Lett. 255, 11-16. doi: 10.1111/j.1574-6968.2005.00043.x of Galati, Romania) for English proofreading this paper is also acknowledged.

\section{SUPPLEMENTARY MATERIAL}

The Supplementary Material for this article can be found online at: http://journal.frontiersin.org/article/10.3389/fmicb. 2016.00390

Supplementary Figure 1 | S. aureus biofilm development. Biomass accumulation when using $0.4 \%$ glucose and $4 \% \mathrm{NaCl}$ to the standard TSB (left). Biofilm formation overtime using TSBG (right). Bars represent the means of the $\mathrm{OD}$ value \pm standard deviation (SD) evaluated in three independent measures obtained upon different treatments tested, as indicated. Values of negative controls have been subtracted from the shown values.

Marques, S. C., Rezende, J. G., Alves, L. A., de Freitas Silva, B. C., and Abreu, L. R., Piccolil, R. H. (2007). Formation of biofilms by Staphylococcus aureus on stainless steel and glass surfaces and its resistance to some selected chemical sanitizers. Brazil. J. Microbiol. 38, 538-543. doi: 10.1590/S151783822007000300029

Oniciuc, E. A., Ariza-Miguel, J., Bolocan, A. S., Diez-Valcarce, M., Rovira, J., Hernández, M., et al. (2015). Foods from black market at $\mathrm{EU}$ border as a neglected route of potential methicillin-resistant Staphylococcus aureus transmission. Int. J. Food Microbiol. 209, 34-38. doi: 10.1016/j.ijfoodmicro.2014.11.015

Peeters, E., Nelis, H. J., and Coenye, T. (2007). Comparison of multiple methods for quantification of microbial biofilms grown in microtiter plates. J. Microbiol. Methods 72, 157-165. doi: 10.1016/j.mimet.2007.11.010

Santos, V. M., Martins, H. B., Rezende, I. S., Barbosa, M. S., Andrade, E. F. Souza, S. G., et al. (2014). Virulence factor profile of Staphylococcus aureus isolated from bovine milk from Brazil. Food Nutrit. Sci. 5, 1496-1505. doi: 10.4236/fns.2014.515162

Shukla, K. S., and Rao, T. S. (2013). Dispersal of Bap-mediated Staphylococcus aureus biofilm by proteinase K. J. Antibiot. 66, 55-60. doi: 10.1038/ja. 2012.98

Speziale, P., Pietrocola, G., Foster, T. J., and Geoghegan, J. A. (2014). Proteinbased biofilm matrices in Staphylococci. Front. Cell Infect. Microbiol. 4:171. doi: $10.3389 /$ fcimb.2014.00171

Stepanović, S., Vuković, D., Dakić, I., Savić, B., and Švabić-Vlahović, M. (2000). A modified microtiter plate test for quantification of staphylococcal biofilm formation. J. Microbiol. Methods 40, 175-179. doi: 10.1016/S01677012(00)00122-6

Vázquez-Sánchez, D., Habimana, O., and Holck, A. (2013). Impact of foodrelated environmental factors on the adherence and biofilm formation of natural Staphylococcus aureus isolates. Curr. Microbiol. 66, 110-121. doi: $10.1007 /$ s00284-012-0247-8

Wright, C. S. (1984). Structural comparison of the two distinct sugar binding sites in wheat germ agglutinin isolectin II. J. Mol. Biol. 178, 91-104. doi: $10.1016 / 0022-2836(84) 90232-8$

Conflict of Interest Statement: The authors declare that the research was conducted in the absence of any commercial or financial relationships that could be construed as a potential conflict of interest.

Copyright (c) 2016 Oniciuc, Cerca and Nicolau. This is an open-access article distributed under the terms of the Creative Commons Attribution License (CC BY). The use, distribution or reproduction in other forums is permitted, provided the original author(s) or licensor are credited and that the original publication in this journal is cited, in accordance with accepted academic practice. No use, distribution or reproduction is permitted which does not comply with these terms. 